\title{
SENSIBILIDADE IN VITRO DE FUNGOS ISOLADOS DE GRÃOS DE MILHO AO FUNGICIDA AZOXISTROBINA + BENZOVINDIFLUPIR EM DIFERENTES CONCENTRAÇÕES
}

José Roberto Chaves Neto ${ }^{1}$, Ivan Francisco Dressler da Costa ${ }^{2}$, Ricardo Boscaini ${ }^{3}$, Nívea Raquel Ledur ${ }^{4}$, Renato Carnellosso Guerra ${ }^{5}$

${ }^{1}$ Engenheiro Agrônomo, Mestre em Agronomia pela Universidade Federal de Santa Maria UFSM/Campus Santa Maria. Departamento de Defesa Fitossanitária, Clínica Fitossanitária DDF/CF. Campus Universitário - Camobi - Prédio 42 - $1^{\circ}$ andar, Cep: 97.105-900, Santa Maria, RS - Brasil. (jose.chavesneto@gmail.com).

${ }^{2}$ Engenheiro Agrônomo, Doutor, Professor Associado do Departamento de Defesa Fitossanitária da Universidade Federal de Santa Maria, Rio Grande do Sul, Brasil.

${ }^{3}$ Graduando em Agronomia, Universidade Federal de Santa Maria - Rio Grande do Sul Brasil.

${ }^{4}$ Graduanda em Agronomia, Universidade Federal de Santa Maria - Rio Grande do Sul Brasil.

${ }^{5}$ Engenheiro Agrônomo, Mestrando em Agronomia, Universidade Federal de Santa Maria, Rio Grande do Sul - Brasil.

Recebido em: 08/04/2016 - Aprovado em: 30/05/2016 - Publicado em: 20/06/2016 DOI: 10.18677/Enciclopedia_Biosfera_2016_106

\begin{abstract}
RESUMO
O controle químico sob aplicação de fungicidas via foliar é uma das estratégias mais utilizadas para o controle das podridões de grãos e espiga, causadas por fungos dos gêneros Aspergillus sp., Fusarium spp. e Penicillium sp. Desse modo este trabalho teve como objetivo determinar in vitro a sensibilidade de fungos dos gêneros Penicillium sp., Fusarium spp. e Aspergillus sp. ao fungicida Azoxistrobina + Benzovindiflupir em diferentes concentrações pelo crescimento micelial (CM), porcentagem de inibição de crescimento micelial (PICM) e índice de velocidade do crescimento micelial (IVCM). A sensibilidade dos fungos ao fungicida Azoxistrobina + Benzovindiflupir foi testada nas concentrações de 10, 50, 100, 500, 1000 ppm (além do controle). O delineamento experimental foi inteiramente casualizado, em quatro repetições. Observou-se para crescimento micelial, porcentagem de inibição de crescimento micelial e índice de velocidade do crescimento micelial de fungos dos gêneros Penicillium sp., Fusarium spp. e Aspergillus sp., diferença significativa entre as concentrações do fungicida Azoxistrobina + Benzovindiflupir. O crescimento dos fungos Penicillium sp., Fusarium spp. e Aspergillus sp., de modo geral é inversamente proporcional à concentração do fungicida utilizada, isto é, quanto maior a concentração do fungicida, menor o crescimento micelial do fungo. O fungo Aspergillus sp. foi o que apresentou a maior inibição do crescimento micelial in vitro na presença do fungicida Azoxistrobina + Benzovindiflupir que apresenta em sua formulação um princípio ativo pertencente ao grupo químico das estrobilurinas. De modo geral, ocorreu redução do índice de velocidade média de crescimento micelial dos fungos Penicillium sp., Fusarium spp. e Aspergillus sp. em paralelo ao aumento da concentração do fungicida.
\end{abstract}

PALAVRAS-CHAVE: grãos ardidos, podridão da espiga, sensibilidade a fungicida. 


\title{
SENSITIVITY IN VITRO FUNGI ISOLATED FROM CORN GRITS THE FUNGICIDE AZOXYSTROBIN + BENZOVINDIFLUPIR IN DIFFERENT STRENGTHS
}

\begin{abstract}
Chemical control in applying foliar fungicides is one of the strategies most used for the control of rotting grain and spike caused by fungi of the genus Aspergillus sp., Fusarium spp. and Penicillium sp., among others. In this way this work was to determine in vitro sensitivity of fungi of the genus Penicillium sp., Fusarium spp. and Aspergillus sp. the fungicide Azoxystrobin + Benzovindiflupir in different concentrations the mycelial growth $(\mathrm{CM})$, percentage inhibition of mycelial growth (PICM) and speed index of mycelial growth (MIGS). The sensitivity of fungi to fungicides Benzovindiflupir + Azoxystrobin was tested at concentrations of 10, 50, 100, 500, 1000 ppm (plus control). The experimental design was completely randomized, with four replications. It was observed for mycelial growth, percentage inhibition of mycelial growth and speed index of mycelial growth of fungi of the genus Penicillium sp., Fusarium spp. and Aspergillus sp., a significant difference between the dose of Azoxystrobin + Benzovindiflupir fungicide. The growth of the fungus Penicillium sp., Fusarium spp. and Aspergillus sp., generally is inversely proportional to the concentration of the fungicide used, i.e. the higher the concentration of the fungicide, the lower the mycelial growth. The fungus Aspergillus sp. it was presented the highest mycelial growth inhibition in vitro in Azoxystrobin + Benzovindiflupir fungicide presence that has in its formula one active ingredient belonging to the chemical group of strobilurins. In general, there was a reduction of the average speed rate of mycelial growth of the fungus Penicillium sp., Fusarium spp. and Aspergillus sp. Parallel to the increase of the fungicide concentration.
\end{abstract}

KEYWORDS: rot grains, cob rot, fungicide sensitivity.

\section{INTRODUÇÃO}

O aumento das áreas plantadas de milho, à falta de rotação de culturas e as condições climáticas favoráveis, tem favorecido o aparecimento de diversas doenças, destacando-se as podridões de grãos e espigas, por causarem danos diretos sobre a qualidade dos grãos, devido ao aparecimento do complexo "grãos ardidos". Estas doenças, no Brasil, são causadas por fungos dos gêneros Fusarium verticilioides, Pennicillium spp., Aspergillus flavus, Stenocarpella maydis, Stenocarpella macrospora, entre outros (NASCIMENTO \& MORAES, 2011; CATÃO et al., 2013).

Uma das principais estratégias de controle das podridões de grãos e espiga é a rotação de cultura, devido ao fato de que a principal fonte de inóculo primário dos fungos são os restos culturais infectados (CASA et al., 2006; BARROS \& JULIATTI, 2012). A implantação da semeadura direta na cultura do milho vem sendo cada dia mais utilizada e difundida, tendo assim um aumento gradativo dos restos culturais que permanecem no solo, provocando uma maior incidência e severidade das doenças em milho (BRITO et al., 2013).

Associado a rotação de cultura tem-se também o controle químico, que é realizado com aplicação foliar de fungicidas. $O$ uso de fungicidas é um método eficaz para o controle de inúmeras doenças, dentre elas as podridões de grãos e espiga, sob aplicação foliar na cultura do milho. A facilidade de aplicação dos fungicidas como também aos resultados eficazes, justificam a difundida utilização destes produtos por parte da maioria dos produtores nas últimas décadas (BRITO et al., 2012; MARTINS \& MARTINS, 2013; LOPES et al., 2015). 
Dentre os grupos químicos de fungicidas os mais utilizados isoladamente ou em misturas pré-fabricadas são as estrobilurinas (inibidores da respiração mitocondrial) e os triazóis (inibidores da síntese de esteróis). Os triazóis tem sua ação em fases mais avançadas do ciclo de vida dos patógenos, ou seja, na colonização ou crescimento micelial e na pré-esporulação. Por outro lado, as estrobirulinas tem sua ação estabelecida nas fases inicias do ciclo, que envolve a germinação dos esporos (GHINI \& KIMATI, 2009; BAMPI et al., 2013).

Trabalhos com Phakopsora pachyrhizi no Brasil demonstram a perda de sensibilidade do fungo a alguns fungicidas utilizados para o controle da doença (ALVIM et al., 2009; GARCÉS-FIALLOS \& FORCELINI, 2013) o que gera uma redução da eficiência destes nas condições de campo (GHINI \& KIMATI, 2009). Segundo RODRIGUES et al. (2007), os fungicidas sistêmicos apresentam uma maior especificidade de ação, agindo sobre rotas metabólicas ou proteínas específicas, fazendo com que apresentem um alto risco de resistência adquirida pelo fungo.

De acordo com REIS et al. (2010), a fungitoxicidade de fungicidas é uma propriedade inerente a uma substância química, sendo definida como a toxicidade aos fungos em baixas concentrações, reduzindo ou inibindo o desenvolvimento desses microorganismos. Em outras palavras uma substância é considerada fungicida quando atua em concentrações baixas. Dentre os parâmetros que podem definir a fungitoxicidade de uma substância química, tem-se $\mathrm{Cl} 50$ (concentração que promove a inibição de $50 \%$ do desenvolvimento dos microorganismos). Valores baixos de $\mathrm{Cl} 50$ indica alta ação fungicida. A Cl50 é especifica para uma determinada substância química e um determinado patógeno, e pode ter seu valor alterado com o tempo de uso (FRAC, 2009; BAMPI et al., 2013).

Com base no exposto, o objetivo deste trabalho foi determinar in vitro a sensibilidade de fungos dos gêneros Aspergillus sp., Fusarium spp. e Penicillium sp. ao fungicida Azoxistrobina + Benzovindiflupir quantificando o crescimento micelial, a inibição do crescimento micelial e o índice de velocidade do crescimento micelial.

\section{MATERIAL E MÉTODOS}

Os ensaios foram conduzidos na Clínica Fitossanitária do Departamento de Defesa Fitossanitária do Centro de Ciências Rurais da Universidade Federal de Santa Maria, Santa Maria, RS, no período de Julho a agosto de 2015. Foram utilizados isolados de fungos associados a grãos de milho dos híbridos $B G 7051 \mathrm{H} \mathrm{e}$ BG7060HR naturalmente infectados, provenientes de áreas experimentais na safra agrícola 2014/15, localizadas no município de Cruz Alta, RS.

$\mathrm{O}$ isolamento dos fungos dos gêneros Penicillium sp., Fusarium spp. e Aspergillus sp., realizados ao final da avaliação de sanidade de grãos, que seguiu as recomendações para análise de sementes do Ministério da Agricultura (BRASIL, 2009). Seguindo metodologia citada por GARCIA et al. (2012), após o período de incubação em câmara úmida, esporos dos fungos oriundos dos grãos infestados, foram removidos com auxílio de uma agulha histológica e transferidos para placas de Petri contendo meio de cultura batata-dextrose-ágar (BDA) e cultivado por 7 dias a temperatura de $25^{\circ} \mathrm{C}$ e fotoperíodo de $12 \mathrm{~h}$. Ao verificar-se a produção de micélio, realizou-se em câmara de fluxo laminar a repicagem, onde discos de micélio foram transferidos para uma nova placa contendo BDA, estas foram armazenadas por 7 dias nas mesmas condições descritas anteriormente visando a obtenção de cultura puras, em seguida, foi escolhida uma colônia desenvolvida de cada um dos fungos isolados, com as quais se trabalhou no transcurso dos ensaios. 
Os fungicidas utilizados nos ensaios foram Azoxistrobina + Benzovindiflupir (300 g + $150 \mathrm{~g}$, respectivamente), de sensibilidade in vitro para cada fungo isolado, em cinco concentrações distintas e uma testemunha sem fungicida. Com base na metodologia descrita por LOPES, et al. (2015), as diferentes concentrações foram obtidas a partir de uma solução estoque (SE) de 1000 ppm de cada produto comercial (fungicidas). Foram realizadas diluições das SE em água destilada e estéril, para obtenção das concentrações 10, 50, 100 e 500 ppm.

A mistura das diferentes concentrações do fungicida com o meio de cultura BDA foi realizada em câmara de fluxo, adicionados $20 \mathrm{~mL}$ da mistura BDA (ainda se em fase líquida, após a esterilização, com temperatura de 38 a $45^{\circ} \mathrm{C}$ ) + diferentes concentrações do fungicida em cada placa de Petri de $9 \mathrm{~cm}$ de diâmetro. Após a solidificação das placas Petri contendo BDA mais as diferentes concentrações do fungicida, foram transferidos discos de $5 \mathrm{~mm}$ contendo micélios em crescimento ativo em BDA dos três isolados, em separado. A testemunha consistiu em BDA sem fungicida. As placas foram mantidas em incubação por dez dias, a temperatura de $25^{\circ} \pm 2{ }^{\circ} \mathrm{C}$ e fotoperíodo de $12 \mathrm{~h}$ (LOPES et al., 2015).

Para avaliação do crescimento micelial dos fungos (CM), foram realizadas medições diárias do crescimento micelial, com auxílio de um paquímetro digital, medindo-se o diâmetro da colônia (média de duas medidas de dois eixos ortogonais) para obter-se a média do crescimento micelial diário. A primeira avaliação foi realizada após 24 horas de incubação das placas, seguindo até que o tratamento testemunha atingisse os bordos da placa (MAIA et al., 2011). O mesmo intervalo de tempo foi adotado para as demais avaliações.

A porcentagem de inibição de crescimento micelial (PICM), foi realizada a partir dos dados diários de crescimento micelial, esta PICM foi obtida através da fórmula descrita por GARCIA et al. (2012):

$$
P I C M=\frac{(D T T-D T Q)}{D T T} X 100
$$

Onde:

$$
\begin{aligned}
& \mathrm{DTT}=\text { diâmetro no tratamento testemunha; } \\
& \mathrm{DTQ}=\text { diâmetro no tratamento químico. }
\end{aligned}
$$

Para o cálculo do índice de velocidade do crescimento micelial (IVCM) utilizou-se a fórmula citada por MAIA et al. (2011):

$I V C M=\sum \frac{(D-D a)}{N}$

Sendo:

$\mathrm{D}=$ diâmetro médio atual da colônia;

$\mathrm{Da}=$ diâmetro médio da colônia do dia anterior;

$\mathrm{N}=$ número de horas ou dias após a inoculação.

O delineamento experimental adotado foi inteiramente casualizado (DIC), em esquema fatorial $3 \times 5$, sendo três fungos (Penicillium sp., Aspergillus sp. e Fusarium sp.) e com 5 concentrações do fungicida (10, 50, 100, 500 e 1000 ppm) e uma testemunha (crescimento micelial somente em meio BDA), em 4 repetições, totalizando 60 placas (amostras).

Os dados foram submetidos à análise de variância pelo teste $\mathrm{F}$ a $5 \%$ de probabilidade de erro. Quando houve variáveis significativas, as médias foram 
submetidas a uma análise de regressão, com auxílio do software Sisvar versão 5.1 (FERREIRA, 2007).

\section{RESULTADOS E DISCUSSÃO}

A análise de variância e os valores médios de porcentagem de inibição de crescimento micelial (PICM) e o índice de velocidade do crescimento micelial (IVCM), estão descritos na tabela 1. Tais resultados mostram que existe diferença significativa $(P \leq 0,05)$ entre as concentrações do fungicida Azoxistrobina + Benzovindiflupir para ambos os fungos estudados. A precisão experimental avaliada pelo coeficiente de variação (CV) variou entre as características. O maior valor de CV foi observado para PICM (26,63\%) e o menor, para o IVCM (10,65\%). Com base nestes baixos valores de CV a premissa de normalidade dos dados foi atendida, não sendo constatado a ocorrência de quaisquer interferência externa significativa que comprometesse a continuidade das análises.

TABELA 1. Resumo da análise de variância e valores médios de crescimento micelial (CM), porcentagem de inibição de crescimento micelial (PICM) e índice de velocidade do crescimento micelial (IVCM) de fungos dos gêneros Penicillium sp., Fusarium ssp. e Aspergillus sp. isolados de grãos de milho. Santa Maria / RS, setembro de 2015.

\begin{tabular}{cccc}
\hline Tratamentos & Diâmetro da colônia $(\mathrm{mm})$ & $\mathrm{PICM}$ & IVCM \\
\hline $\mathrm{F}^{1}$ & & $\mathrm{QM}^{2}$ \\
\hline Fungo $(\mathrm{F})$ & $3782,18^{*}$ & $5607,45^{*}$ & $282,45^{*}$ \\
Concentração $(\mathrm{C})$ & $2142,91^{*}$ & $4470,92^{*}$ & $371,34^{*}$ \\
FxC & $218,05^{*}$ & $502,09^{*}$ & $44,33^{*}$ \\
Erro & 33,01 & 57,73 & 10,65 \\
\hline CV (\%) & 11,39 & 26,63 & 10,65 \\
\hline Média Geral & 50,47 & 28,54 & 14,54 \\
\hline
\end{tabular}

$\left.{ }^{11}\right)$ Teste $F,{ }^{(2)}$ Quadrado médio, * significativo a $5 \%$ e ${ }^{(\text {(NS) }}$ não significativo.

Ao observar a figura $1 \mathrm{~A}$, constatou-se comportamento diferente entre os fungos quando submetidos ao meio de cultura contendo o fungicida Azoxistrobina + Benzovindiflupir. $O$ isolado de Penicillium sp., foi o que apresentou os maiores diâmetros de crescimento micelial, diferindo estatisticamente dos demais, nas diferentes concentrações do fungicida. O isolado de Aspergillus sp. apresentou as menores médias do crescimento micelial, diferindo dos demais expressivamente.

A eficácia dos princípios ativos pertencentes ao grupo químico estrobilurina também foi descrita por LOPES, et al. (2015), que ao avaliarem a sensibilidade de diferentes isolados de Colletotrichum gloeosporioides a fungicidas, constataram que o fungicida que proporcionou um menor crescimento micelial foi o Trifloxistrobina + Tebuconazol, sendo estes princípios ativos pertencentes aos grupos químicos estrobilurina e triazol, respectivamente.

Por outro lado, os dados obtidos neste trabalho contradizem os descritos por ZANCAN et al. (2012), que ao avaliarem a eficácia do controle químico e biológico de Sclerotinia sclerotiorum, constataram para o grupo químico das estrobilurinas, utilizado neste trabalho, uma menor eficácia ao compará-lo com fungicidas sistêmicos.

Como era esperado as maiores concentrações proporcionaram os menores crescimentos miceliais, diferindo estatisticamente da testemunha que apresentou 0 
maior crescimento micelial em relação as diferentes concentrações (Figura 1B). Todas as diferentes concentrações utilizadas do fungicida Azoxistrobina + Benzovindiflupir diferem entre si, ao teste Tukey $(\mathrm{P} \leq 0,05)$.

A concentração de 1000 ppm, apresentou os menores crescimentos miceliais, variando entre 30 e $40 \mathrm{~mm}$, não diferindo da concentração de 500 ppm, porém diferiu estatisticamente das demais concentrações assim como da testemunha que apresentou o maior crescimento micelial (Figura 1B). LOPES, et al. (2015), ao avaliarem a sensibilidade de diferentes isolados de Colletotrichum gloeosporioides a fungicidas, constataram o mesmo comportamento de redução do crescimento micelial em paralelo ao aumento das concentrações dos fungicidas.

Segundo FRAC (2009), existe uma relação entre a redução das concentrações, e a resistência de fungos a determinados fungicidas, o que gera uma redução da sensibilidade ao produto. Visto que na prática a resistência governada por genes maiores ou resistência poligênica respondem diferentemente a alterações nas concentrações. Mais estudos devem ser conduzidos, visando a elucidação desta questão, sobre o efeito da dose no surgimento e manutenção da resistência.
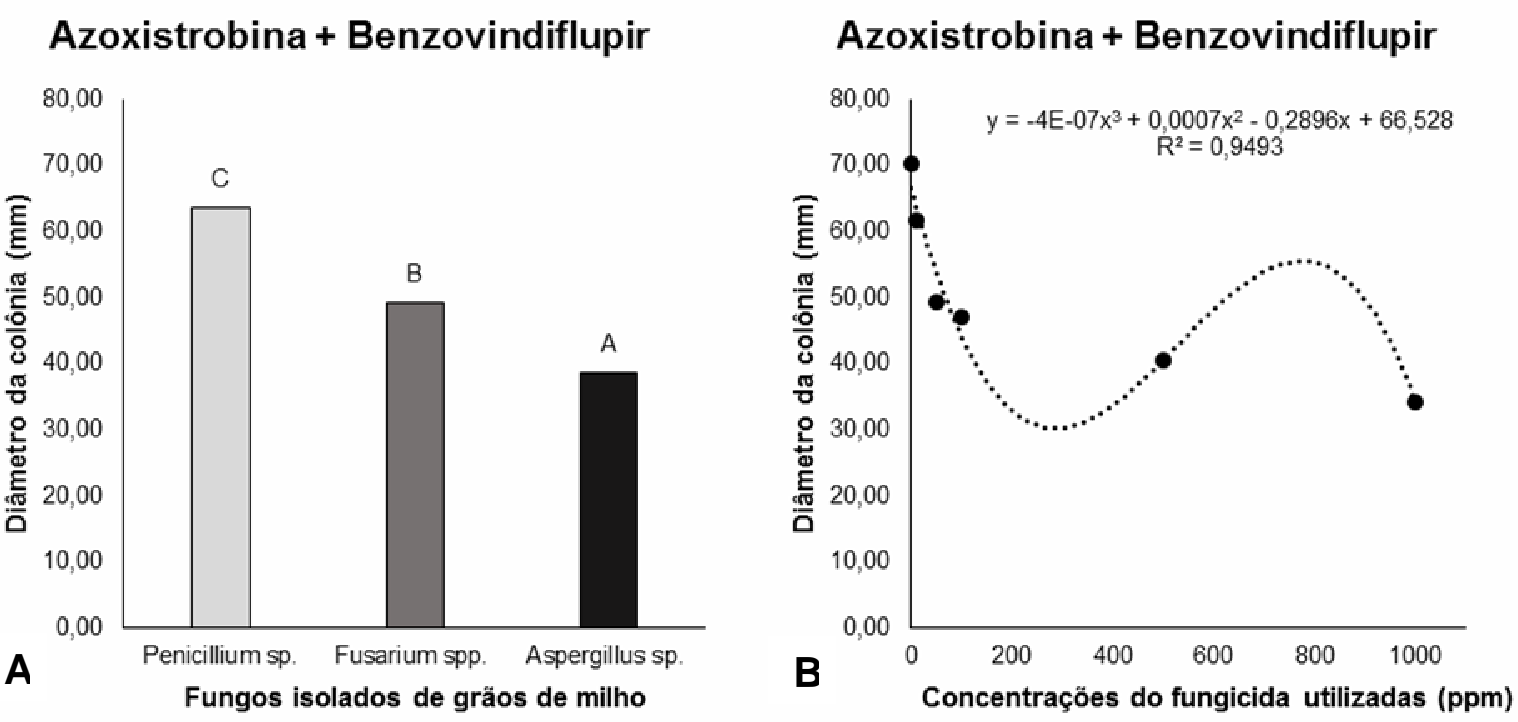

FIGURA 1. Crescimento micelial $(\mathrm{mm})$ de fungos do gênero Penicillium sp., Fusarium spp. e Aspergillus sp. A. diferentes fungos isolados de grãos de milho (Valores seguidos de mesma letra não diferem estatisticamente entre si pelo Teste de Tukey, em nível de significância de $5 \%$.), B. regressão para as diferentes concentrações do fungicida Azoxistrobina + Benzovindiflupir. Santa Maria / RS, setembro de 2015.

Ao analisar a regressão para as diferentes concentrações do fungicida Azoxistrobina + Benzovindiflupir referente ao crescimento micelial $(\mathrm{mm})$, constatouse que houve diferença significativa $(P \leq 0,05)$ entre as concentrações para todos os fungos estudados neste experimento (Figura 2). Para o crescimento micelial do isolado de Penicillium sp., constatou-se que a concentração 1000 ppm, apresentou os menores crescimentos, com média variando de 50 a $60 \mathrm{~mm}$, não diferindo estatisticamente das demais concentrações, mas diferindo expressivamente da concentração de 0 ppm (testemunha, que apresentou uma média de crescimento superior a $70 \mathrm{~mm}$ (Figura 2A).

No isolado de Fusarium spp. as concentrações diferiram entre si, a concentração de 1000 ppm, foi a que apresentou o menor crescimento micelial, com ENCICLOPÉDIA BIOSFERA, Centro Científico Conhecer - Goiânia, v.13 n.23; p.1216 
média pouco acima de $30 \mathrm{~mm}$, não diferiu estatisticamente das concentrações de 500 e 100 ppm (Figura 2B). Quanto ao isolado de Aspergillus sp. as concentrações que apresentaram os menores crescimentos miceliais foram as de 1000 e 500 ppm, com médias variando entre 10 e $20 \mathrm{~mm}$, diferindo estatisticamente da testemunha que apresentou o maior crescimento micelial em relação as diferentes concentrações (Figura 2C).

Este mesmo comportamento em relação as concentrações, foi descrito por LOPES, et al. (2015), que ao avaliarem a sensibilidade de diferentes isolados de Colletotrichum gloeosporioides a fungicidas, observaram diferenças entre as concentrações e verificaram que quanto maior a concentração menor o crescimento micelial. BAMPI et al. (2013), ao estabelecerem a sensibilidade de diferentes isolados de Stenocarpella macrospora a fungicidas pertencentes a diferentes grupos químicos, dentre eles as estrobilurinas, constataram que os fungicidas do grupo das estrobilurinas, mesmo em baixas concentrações inibição do crescimento do micélio e a geminação de conídios.

Penicillium sp.
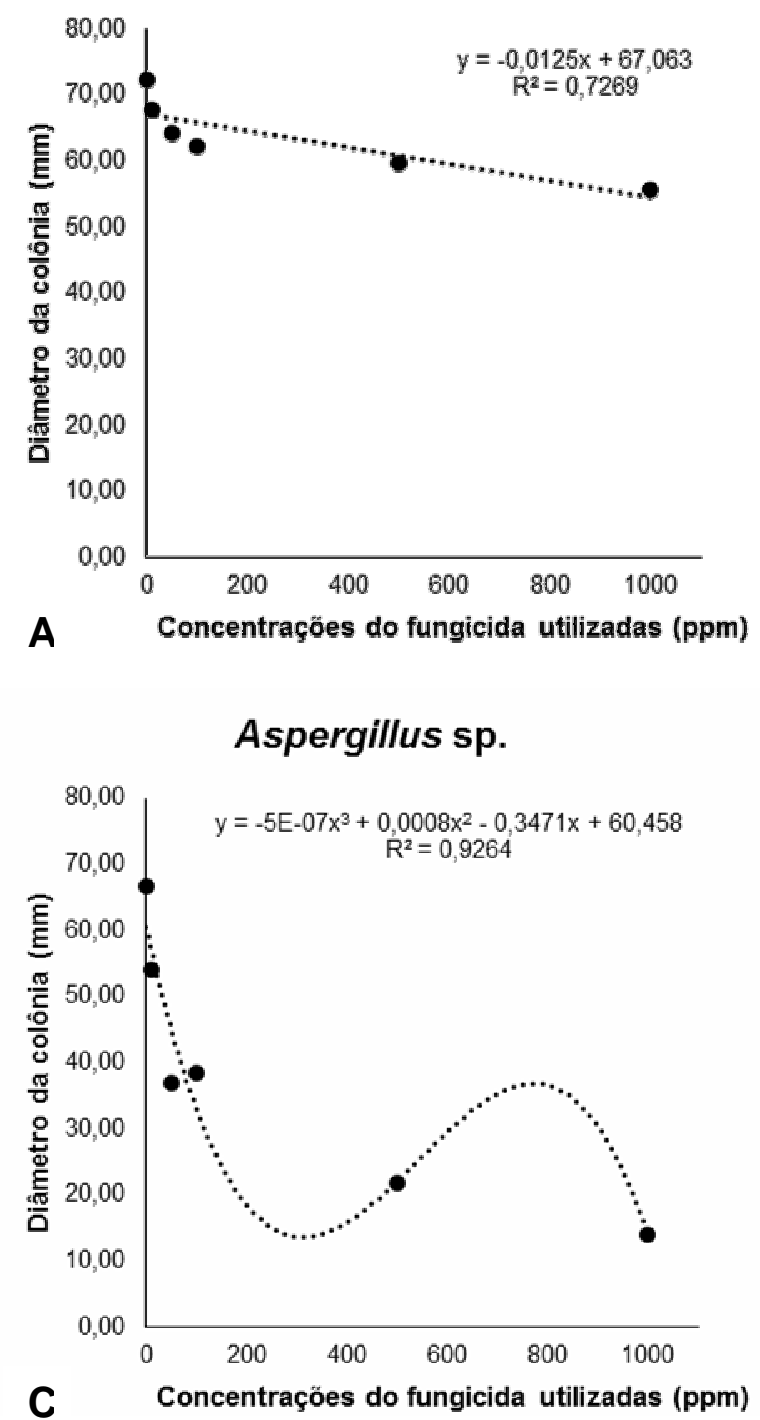

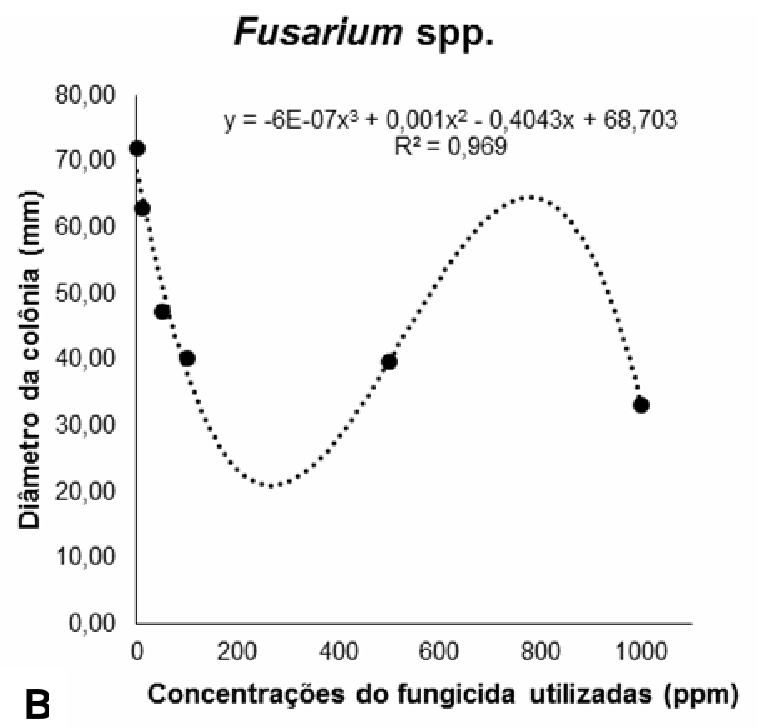

IGURA 2. Regressão para as diferentes concentrações (ppm) do fungicida Azoxistrobina + Benzovindiflupir referente ao crescimento micelial $(\mathrm{mm})$ de fungos do gênero Penicillium sp., Fusarium spp. e Aspergillus sp. Santa Maria / RS, setembro de 2015. 
Para a porcentagem de inibição do crescimento micelial, observou-se diferença estatística $(P \leq 0,05)$, tanto entre os fungos como entre as diferentes concentrações do fungicida Azoxistrobina + Benzovindiflupir (Figura 3, 4). Quanto ao fator fungo, verificou-se que o isolado de Aspergillus sp. mostrou maior sensibilidade ao fungicida Azoxistrobina + Benzovindiflupir, devido ter apresentado a maior porcentagem de inibição de crescimento micelial em relação aos demais fungos. $O$ isolado de Penicillium sp. apresentou a maior porcentagem de inibição de crescimento, e consequentemente uma menor sensibilidade ao fungicida avaliado (Figura 3A).

Segundo BAMPI et al. (2013), as diferenças de fungitoxicidade de um mesmo produto sobre a inibição de crescimento micelial de diferentes fungos, podem estar relacionadas à variabilidade genética do fungo e, o que irá caracterizar à maior ou menor sensibilidade desses isolados a um determinado fungicida.

Para o fator concentração, também foi constatado diferenças significativas $(P \leq 0,05)$, de modo geral ocorreu a redução do crescimento micelial em paralelo ao aumento da concentração do fungicida Azoxistrobina + Benzovindiflupir. A maior porcetagem de inibição do crescimento foi constatada na concentração de 1000 e 500 ppm, com superior a 50\%, não diferindo da concentração de 500 ppm. A menor porcentagem de inibição do crescimento foi obtida na concentração de 0 ppm (testemunha) (Figura 3B).

LOPES et al. (2015), também relatam a eficácia de princípios ativos pertencentes ao grupo químico estrobilurina, visto que o fungicida que promoveu a maior inibição do crescimento micelial foi o Nativo (Trifloxistrobina+Tebuconazol).
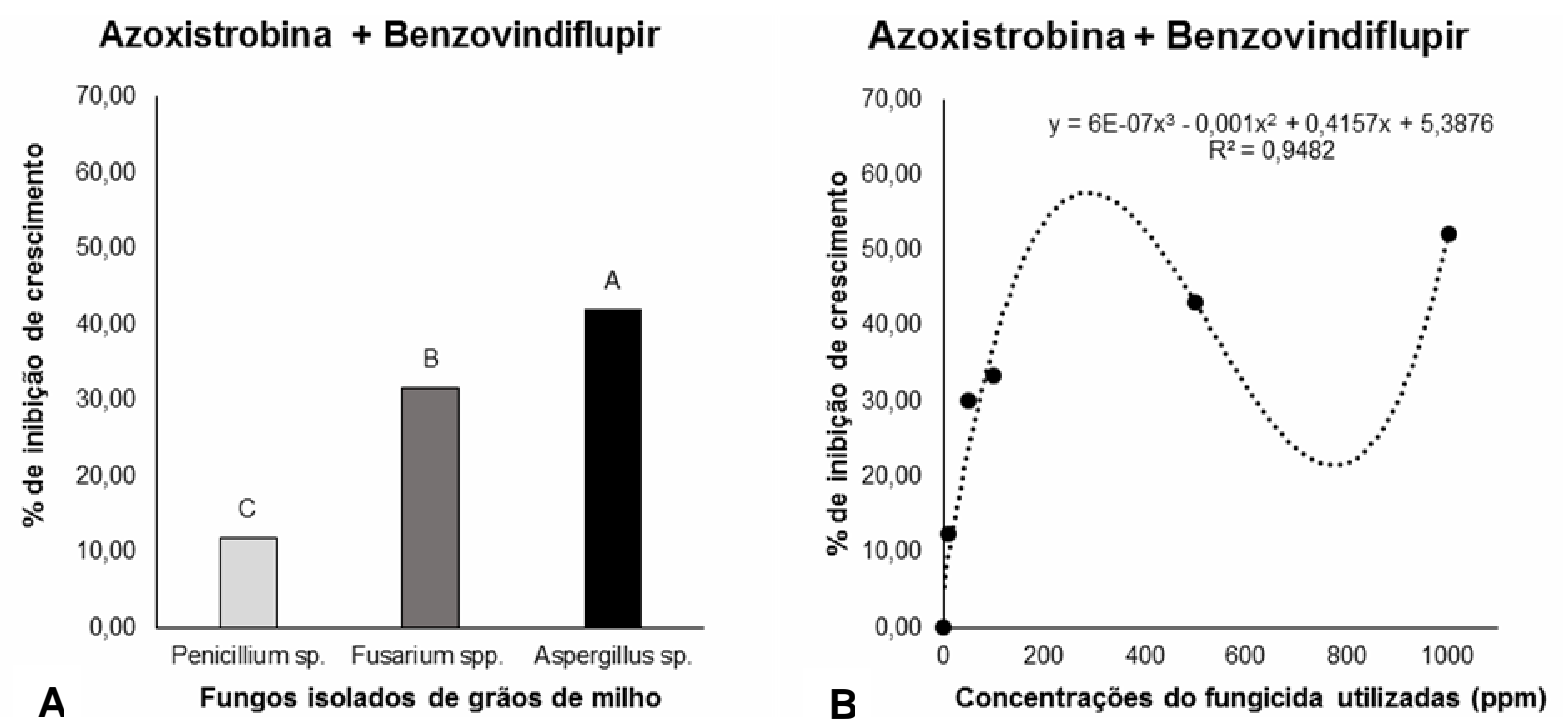

FIvURA 3. Porcentagem de inibição do crescımento micelial (\%) de fungos do gênero Penicillium sp., Fusarium spp. e Aspergillus sp. A. diferentes fungos isolados de grãos de milho (Valores seguidos de mesma letra não diferem estatisticamente entre si pelo Teste de Tukey, em nível de significância de 5\%.), B. regressão para as diferentes concentrações do fungicida Azoxistrobina + Benzovindiflupir. Santa Maria / RS, setembro de 2015.

Ao analisar a regressão para as diferentes concentrações do fungicida Azoxistrobina + Benzovindiflupir referente a porcentagem de inibição do crescimento micelial (\%), constatou-se que houve diferença significativa $(P \leq 0,05)$ entre as concentrações para todos os fungos estudados neste experimento (Figura 4).

Para o isolado Penicillium sp., as maiores porcentagens de inibição do crescimento micelial foram observadas na concentração de 1000 ppm, com média ENCICLOPÉDIA BIOSFERA, Centro Científico Conhecer - Goiânia, v.13 n.23; p.1218 2016 
superior a 20\%, não diferindo estatisticamente das concentrações de 500, 100 e 50 ppm. A menor porcentagem de inibição foi constatada na concentração de 0 ppm (testemunha) (Figura 4A).

Para os resultados do isolado Fusarium spp., constatou-se que as concentrações de 100, 500 e 1000 ppm foram as que apresentaram as maiores porcentagens de inibição do crescimento micelial, com porcentagens superiores a $40 \%$. A concentração de $0 \mathrm{ppm}$ (testemunha) foi a que obteve a menor porcentagem de inibição (Figura 4B).

Para o isolado Aspergillus sp., observou-se que as concentrações que apresentaram as maiores porcentagens de inibição do crescimento micelial foram as de 500 e 1000 ppm, com média superior a 60\%. A concentração que obteve a menor porcentagem de inibição foi a de 0 ppm (testemunha) (Figura 4C).

Testes realizados a campo para verificar a eficácia da aplicação de um fungicida pertencente ao grupo químico das estrobirulinas e triazóis (azoxistrobina + ciproconazol), na presença de fungos, em grãos colhidos de milho, mostraram que, ocorreu uma menor incidência do fungo Fusarium sp., no entanto, quanto a incidência de Aspergillus sp. e Penicillium sp. nos grãos, não houve influência (STEFANELLO et al., 2012). O mesmo comportamento foi observado por JULIATTI et al. (2007), que ao avaliarem o efeito da aplicação de fungicidas via foliar, na incidência do fungo Fusarium moniliforme em grãos de milho, constataram que a menor incidência, foi quando aplicado o fungicida Azoxistrobina + Ciproconazole.

Penicillium sp.
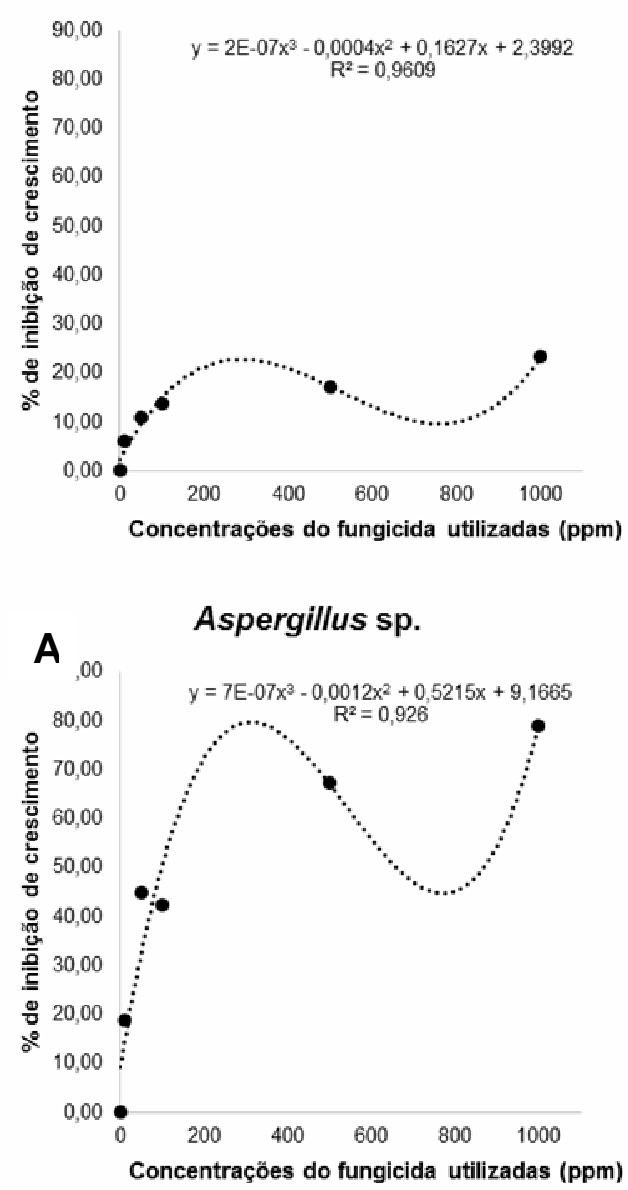

Fusarium spp.

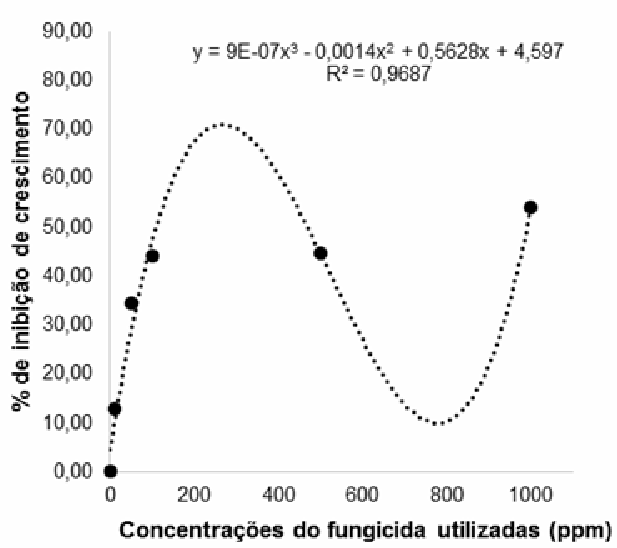

B

FIGURA 4. Regressão para as diferentes concentrações (ppm) do fungicida Azoxistrobina + Benzovindiflupir referente a porcentagem de inibição do crescimento micelial (\%) de fungos do gênero Penicillium sp., Fusarium spp. e Aspergillus sp. Santa Maria / RS, setembro de 2015. 
Observou-se para o índice de velocidade de crescimento micelial (IVCM), diferenças estatísticas entre os fungos estudados e entre as concentrações do fungicida Azoxistrobina + Benzovindiflupir utilizadas, assim como para interação concentração $x$ fungo (Figura 5 e 6).

Quanto ao fator fungo, o menor índice de velocidade de crescimento micelial foi constatado para o isolado Aspergillus sp., com $11,39 \mathrm{~mm} / \mathrm{dia}^{-1}$. Os maiores índices de crescimento foram observados no isolado Penicillium sp., com 18,20 $\mathrm{mm} / \mathrm{dia}^{-1}$ (Tabela 5A).

Para o fator concentração, constatou-se que de modo geral ocorreu redução significativa do índice de velocidade do crescimento micelial em paralelo ao aumento da concentração (Figura 5B). Visto que 0 menor índice de velocidade de crescimento foi observado na dosagem de $1000 \mathrm{ppm}$, com 10,43 mm/dia ${ }^{-1}$, não diferindo estatisticamente das concentrações de 500, 100 e 50 ppm, com índices variando entre 10,70 a $12,14 \mathrm{~mm} / \mathrm{dia}^{-1}$. A concentração de $0 \mathrm{ppm}$ (testemunha), foi a que obteve o maior índice, $23,95 \mathrm{~mm} / \mathrm{dia}^{-1}$ (Figura 5B).

Os resutados encontrados neste trabalho diferem dos obtidos por MAIA et al. (2011), que ao avaliarem o efeito da temperatura no crescimento micelial, produção e germinação de conídios de Colletotrichum spp., constataram que não houve interação significativa para o índice de crescimento micelial (IVCM) considerando os isolados analisados e a temperatura.
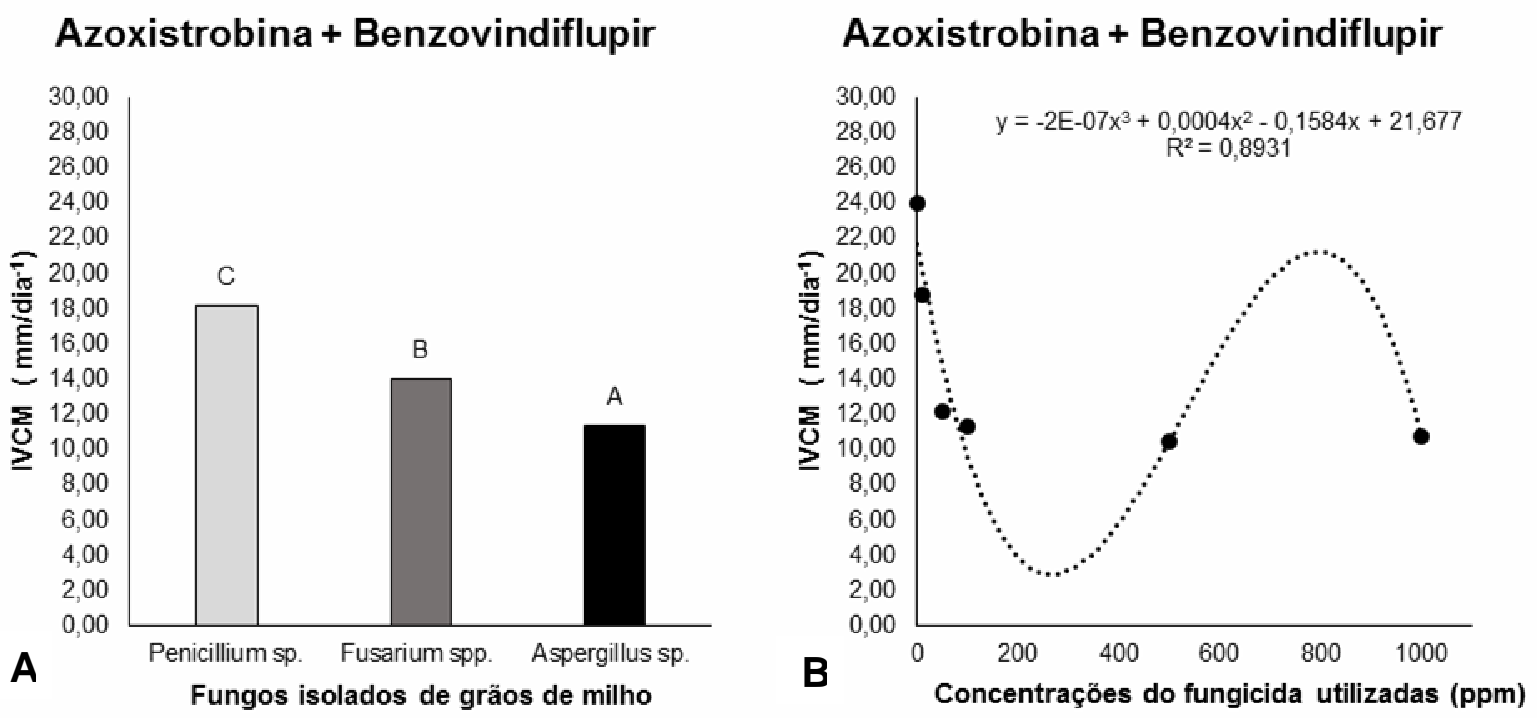

FIGURA 5. Índice de velocidade média de crescimento micelial $\left(\mathrm{mm} / \mathrm{dia}^{-1}\right)$ de fungos do gênero Penicillium sp., Fusarium spp. e Aspergillus sp. A. diferentes fungos isolados de grãos de milho (Valores seguidos de mesma letra não diferem estatisticamente entre si pelo Teste de Tukey, em nível de significância de $5 \%$.), B. regressão para as diferentes concentrações do fungicida Azoxistrobina + Benzovindiflupir. Santa Maria / RS, setembro de 2015.

Quanto a regressão para as diferentes concentrações do fungicida Azoxistrobina + Benzovindiflupir referente a índice de velocidade média de crescimento micelial $\left(\mathrm{mm} / \mathrm{dia}^{-1}\right)$, constatou-se que houve diferença significativa $(P \leq 0,05)$ entre as concentrações para todos os fungos estudados neste experimento (Figura 6). 
Para os resultados do fungo Penicillium sp., observou-se que a concentração de $1000 \mathrm{ppm}$ proporcionou o menor índice de crescimento micelial, com média de $16,03 \mathrm{~mm} / \mathrm{dia}^{-1}$, não diferindo estatisticamente das concentrações de 500, 100 e 50 ppm, com média variando entre 16,32 e 17,56 mm/dia ${ }^{-1}$ (Tabela 6A).

No fungo Fusarium spp. constatou-se que a concentração de 1000 ppm, foi a que apresentou o menor índice de crescimento micelial, com média de $8,66 \mathrm{~mm} / \mathrm{dia}^{-}$ 1 , não diferindo estatisticamente das concentrações de 500, 100 e 50 ppm, com média variando entre 8,84 e 11,83 mm/dia ${ }^{-1}$. A concentração de $0 \mathrm{ppm}$ (testemunha) foi a que que apresentou o maior índice (Tabela 6B).

Quanto ao fungo Aspergillus sp. verificou-se que a concentração de 1000 ppm, foi a que apresentou o menor índice de crescimento micelial, com média de $3,77 \mathrm{~mm} / \mathrm{dia}^{-1}$, não diferindo estatisticamente da concentração de $500 \mathrm{ppm}$, com média de $4,88 \mathrm{~mm} / \mathrm{dia}^{-1}$. A concentração que apresentou o maior índice foi a de 0 ppm (testemunha), com média de 24,76 mm/dia ${ }^{-1}$ (Tabela $6 \mathrm{C}$ ).
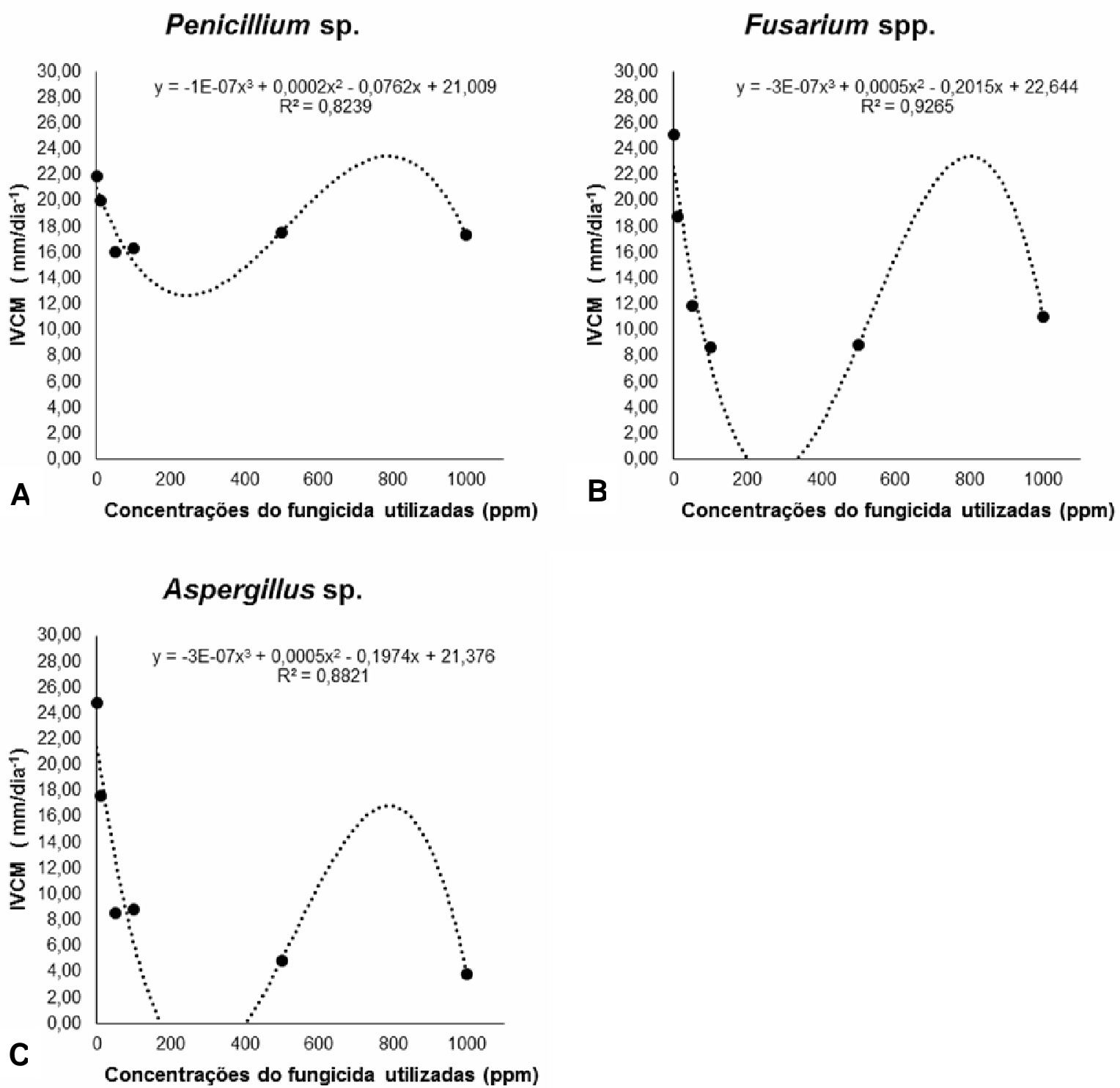

FIGURA 6. Regressão para as diferentes concentrações (ppm) do fungicida Azoxistrobina + Benzovindiflupir referente a Índice de velocidade média de crescimento micelial $\left(\mathrm{mm} / \mathrm{dia}^{-1}\right)$ de fungos do gênero Penicillium sp., Fusarium spp. e Aspergillus sp. Santa Maria / RS, setembro de 2015. 
Atualmente além da preocupação com o aumento na incidência de grãos ardidos na cultura do milho, que tem limites máximos aceitos pelo mercado externo e interno, nos últimos anos tem-se realizado pesquisas sobre a contaminação de grãos por micotoxinas, que está diretamente relacionado a incidência de fungos. Devido ao fato de que o controle químico ainda é o mais utilizado, é de extrema necessidade o monitoramento da sensibilidade dos fungos, principalmente em regiões onde a demanda pelo uso de fungicidas na cultura do milho é intensa (MENDES et al., 2012).

Além do controle químico, outras estratégias estão sendo adotadas pelos produtores, como a utilização de híbridos resistentes, antecipação da colheita, e mais recentemente o uso de métodos alternativos de controle, que minimizem os impactos ao meio ambiente e que sejam eficientes no manejo de doenças, dentre estes métodos destacam-se o uso sustâncias presentes em extratos de plantas, que apresentam potencial fungicida ou fungistático, ou seja, capacidade de controle de fitopatógenos (CELOTO et al., 2008; GARCIA et al., 2012).

\section{CONCLUSÕES}

O crescimento dos fungos Penicillium sp., Fusarium spp. e Aspergillus sp., de modo geral é inversamente proporcional à concentração do fungicida Azoxistrobina + Benzovindiflupir, desse modo, quanto maior a concentração, menor o crescimento micelial do fungo.

O fungo Aspergillus sp. foi o que apresentou a maior inibição micelial in vitro na presença do fungicida Azoxistrobina + Benzovindiflupir que apresenta em sua formulação um princípio ativo pertencente ao grupo químico das estrobilurinas.

De modo geral, ocorreu redução do índice de velocidade média de crescimento micelial dos fungos Penicillium sp., Fusarium spp. e Aspergillus sp. em paralelo ao aumento da concentração do fungicida.

\section{AGRADECIMENTOS}

Os autores agradecem a Cooperativa Central Gaúcha Ltda (CCGL), pela disponibilidade da área e pela ajuda na condução do experimento de campo e a Coordenação de Aperfeiçoamento de Pessoal de Nível Superior (CAPES), pela bolsa de estudos.

\section{REFERÊNCIAS}

ALVIM, M. S.; JULIATTI, F. C.; ALVIM, J. R. M. G.; PARREIRA, F. O. S.; SILVA, O. S.; JULIATTI, B. C. M.; REZENDE, A. A.; MARTINS, J. A. S.; SAGATA, E. Avaliação de fungicidas registrados no MAPA no controle da ferrugem da soja. Tropical Plant Pathology, v. 34, p. S84, 2009.

BAMPI, D.; CASA, R. T.; WORDELL FILHO, J. A.; BLUM, M. M. C.; CAMARGO, M. $P$. Sensibilidade de Stenocarpella macrospora a fungicidas. Bioscience Journal, v. 29, n. 4, p. 787-795, 2013.

BARROS, F. C.; JULIATTI, F. C. Levantamento de fungos em amostras recebidas no Laboratório de micologia e proteção de plantas da Universidade federal de uberlândia, no período 2001-2008. Bioscience Journal, v. 28, n. 1, p. 77-86, 2012.

BRASIL. Ministério da Agricultura, Pecuária e Abastecimento. Regras para análise de sementes. Ministério da Agricultura, Pecuária e Abastecimento. Secretaria de Defesa Agropecuária. Brasília, DF: Mapa/ACS, 395p., 2009. 
BRITO, A. B.; PINHO, R. V. G.; PEREIRA, J. L. A. R.; BALESTRE, M. Controle químico da Cercosporiose, Mancha-Branca e dos Grãos Ardidos em milho. Revista Ceres, v. 60, n. 5, p. 629-635, 2013.

BRITO, A. H.; PEREIRA, J. L. A. R.; PINHO, R. G. V.; BALESTRE, M. Controle químico de doenças foliares e grãos ardidos em milho (Zea mays L.). Revista Brasileira de Milho e Sorgo, v.11, n.1, p. 49-59, 2012.

CATÃO, H. C. R. M.; MAGALHÃES, H. M.; SALES, N. L. P.; BRANDÃO JUNIOR, D. S.; ROCHA, F. S. Incidência e viabilidade de sementes crioulas de milho naturalmente infestadas com fungos em pré e pós-armazenamento. Ciência Rural, v.43, n.5, 2013.

CELOTO, M. I. B.; PAPA, M. F. S.; SACRAMENTO, L. V. S.; CELOTO, F. J. Atividade antifúngica de extratos de plantas a Colletotrichum gloeosporioides. Acta Scientiarum Agronomy, v. 30, n. 1, p. 151-158, 2008.

FERREIRA, D. F. SISVAR Sistemas de análises de variância para dados balanceados: programa de análises estatísticas e planejamento de experimentos. Software. Versão 5.1. Lavras: UFLA/DEX, 2007.

FRAC Code List: Fungicides sorted by mode of action (including FRAC Code numbering).

<http://www.frac.info/frac/publication/anhang/FRAC_Code_List_2009_web.pdf>.

Acesso em: 01 fev. 2016.

GARCÉS-FIALLOS, F. R.; FORCELINI, C. A. Controle comparativo da ferrugem asiática da soja com fungicida triazol ou mistura de triazol + estrobilurina. Bioscience Journal, v. 29, n. 4, p. 805-815, 2013.

GARCIA, R. A.; JULIATTI, F. C.; BARBOSA, K. A. G.; CASSEMIRO, T. A. Atividade antifúngica de óleo e extratos vegetais sobre Sclerotinia sclerotiorum. Bioscience Journal, v. 28, n. 1, p. 48-57, 2012.

GARCIA, R.A.; JULIATTIF. C.; BARBOSA, K. A. G. Efeito de fungicidas e herbicidas no controle de Sclerotinia sclerotiorum. Bioscience Journal, v. 29, n. 6, p. 19891996, 2013.

GHINI, R.; KIMATI, H. Resistência de fungos a fungicidas. Jaguariuna: Embrapa Meio Ambiente. 78 p. 2009.

LOPES, L. N. S.; SILVA, A. S.; PEREIRA, C. C. O. MENEZES, I. P. P.; MALAFAIA, G.; LIMA, M. L. P. Sensibilidade de isolados de Colletotrichum gloeosporioides a fungicidas. Multi-Science Journal, v.1, n. 1, p. 106-114, 2015.

MAIA, F. G. M.; ARMESTO, C.; ZANCAN, W L. A.; MAIA, J. B.; ABREU, M. S. Efeito da temperatura no crescimento micelial, produção e germinação de conídios de Colletotrichum spp. isolados de mangueira com sintomas de antracnose. Bioscience Journal, v. 27, n. 2, p. 205-210, 2011.

MARTINS, S. C. S.; MARTINS, C. M. Isolamento e controle químico de fungos filamentosos de documentos e obras de arte do Estado do Ceará. Enciclopédia Biosfera, v.9, n.17, p. 2821-2832, 2013. 
MENDES, M. C.; PINHO, R. V. G.; PINHO, E. R. V.; FARIA, M. V. Comportamento de híbridos de milho inoculados com os fungos causadores do complexo grãos ardidos e associação com parâmetros químicos e bioquímicos. Ambiência - Revista do Setor de Ciências Agrárias e Ambientais, v. 8, n. 2, p. 275-292, 2012.

NASCIMENTO, W. M. O.; MORAES, M. H. D. Fungos associados a sementes de açaí: efeito da temperatura e do teor de água das sementes durante 0 armazenamento. Revista Brasileira de Sementes, v. 33, n. 3, p. 415-425. 2011.

REIS, E. M.; REIS, A.C.; CARMONA, M. A. Manual de fungicidas: Guia para controle químico de doenças de plantas. 6o ed. 226p. Passo Fundo. Ed. Universidade de Passo Fundo, 2010.

RODRIGUES, M. B. C. ANDREOTE, F. D.; SPÓSITO, M. B.; AGUILLAR-VILDOSO, C. I.; ARAÚJO, W. L.; PIZZIRANI-KLEINER, A. A. Resistência a benzimidazóis por Guignardia citricarpa. Pesquisa Agropecuária Brasileira, v. 42, n. 3, p. 323-327, 2007.

STEFANELLO, J.;BACHI, L. M. A.; GAVASSONI, W. L.; HIRATA, L. M.; PONTIM, B. C. A. Incidência de fungos em grãos de milho em função de diferentes épocas de aplicação foliar de fungicida. Pesquisa Agropecuária Tropical, v. 42, n. 4, p. 476481, 2012.

ZANCAN, W. L. A.; MACHADO, J. C.; SOUSA, B. F. M.; MATOS, C. S. M. Crescimento micelial, produção e germinação de Escleródios de Sclerotinia sclerotiorum na presença de fungicidas químicos e Trichoderma harzianum. Bioscience Journal, v. 28, n. 5, p.782-789, 2012. 